\title{
CONCORRÊNCIA DESLEAL: ATOS DE IMITAÇÃO NÃO CONFUSIVOS
}

\section{UNFAIR COMPETITOIN: ACTS OF NON-CONFUSIVE IMITATIONS}

${ }^{1}$ José Roberto de Almeida Junior

\section{RESUMO}

Este estudo visa a analisar a concorrência desleal, notadamente, os atos de imitação que não têm como objetivo estabelecer confusão no mercado. Para melhor compreensão do tema, inicia-se o estudo com breve análise do que se entende por concorrência desleal, com destaque para sua difícil definição e amplitude de possibilidades. Nesse ponto, passa-se a procurar por critérios para se apurar a deslealdade, em busca da "qualidade específica". Por fim, o estudo dedica-se a indicar exemplos de condutas desleais, por meios de ato de imitação que não geram confusão, com base nas teorias depreendidas da revisão bibliográfica.

Palavras-chave: Propriedade intelectual, Concorrência desleal, Atos de imitação não confusivos

\begin{abstract}
This study aims to analyze unfair competition, notably, acts of imitation that are not intended to create confusion in the market. For better understanding of the topic, the study begins by analyzing what is meant by unfair competition, highlighting its difficult definition and range of possibilities. At this point, it looks for criteria to investigate such unfairness, seeking the "specific quality". Finally, the study is dedicated to give examples of unfair conduct by means of act of imitation that does not generate confusion based on the results obtained on the bibliography review.
\end{abstract}

Keywords: Intelectual property, Unfair competition, Acts of non- confusive imitations

${ }^{1}$ Mestrando em Direito pela Universidade do Estado do Rio de Janeiro - UERJ, Rio de Janeiro, (Brasil). Advogado e Agente da Propriedade Industrial. E-mail: roberto.almeida2@ gmail.com 


\section{INTRODUÇÃO}

Com o rápido desenvolvimento do comércio e a agilidade na troca de informações, uso cada vez maior das ferramentas disponíveis pela rede mundial de computadores e capacidade tecnológica em crescimento sem precedentes, podemos perceber um grande aumento na concorrência entre as empresas, resultando na sofisticação de seus produtos e serviços em busca de um diferencial, algo que seus concorrentes não ofereçam, com o intuito de atrair a atenção do consumidor.

No entanto, buscar um diferencial não se trata de uma tarefa das mais fáceis. Se destacar no mercado, principalmente nos dias de hoje, está menos associado a sorte e sim ao investimento do comerciante, seja em mão de obra qualificada, insumos de qualidade ou em publicidade.

Para se diferenciar no mercado, o concorrente deve investir na criação, sabedor do risco que a inovação representa. Afinal, nem toda mudança, ainda que, objetivamente, seja melhor e mais eficiente, é aceita de bom grado pelo consumidor. Não raramente, a percepção de qualidade pelo consumidor apenas ocorrer após um período de esforço publicitário.

Por vezes, o caminho escolhido por um competidor em determinado mercado é imitar o que o líder, ou outro competidor de mais sucesso, fez. Esse comportamento, por si só, não é condenado. É um comportamento natural e até esperado, que acirra a concorrência ao não deixar o mercado em situação confortável motivando a todos para uma constante evolução.

No entanto, como será visto no decorrer desse trabalho, por vezes o ato de imitação pode ser considerado como um ato de concorrência desleal. A deslealdade é uma qualidade específica de certos atos de imitação que não é benéfica para o mercado.

Nesse sentido, a revisão bibliográfica que resultou no presente trabalho teve como foco os atos de imitação, que podem ser considerados como atos de concorrência desleal, embora não gerem confusão para o consumidor.

Com efeito, não se pretende aqui contrariar pensamentos já consagrados na doutrina brasileira, que apontam a suscetibilidade de confusão como ferramenta para caracterização da concorrência desleal.

$\mathrm{Na}$ realidade, a pesquisa conduzida teve como objetivo verificar casos excepcionais em que poderá haver deslealdade na conduta do concorrente, ao imitar elementos de terceiros, mesmo sem o objetivo de confundir a clientela, ou seja, sem induzi-la a tomar um 
produto/serviço pelo outro. Em tais hipóteses, há intenção de reduzir custos artificialmente, aproveitar-se do prestígio, investimento e/ou contribuição alheia de forma não esperada.

Para essa finalidade, a pesquisa teve como proposta fazer coro aos doutrinadores e juízes que já se manifestaram sobre o tema, com o intuito de difundir seus entendimentos e agrupá-los de modo a se obter uma base sólida para apurar a deslealdade de tais atos, que, como escrito linhas atrás, possuem caráter excepcional.

Desse modo, o presente estudo passará por uma breve exposição sobre o que se entende como concorrência desleal.

Após, por meio da colaboração de doutrinadores brasileiros e estrangeiros, poderão ser observados alguns critérios que qualificaram o ato de imitação como desleal. Conforme se depreende do título desse estudo, dar-se-á foco, propositalmente, na apuração dos atos desleais que não visam a gerar confusão. Uma vez que a confusão, pacificamente, não é benéfica para o mercado, a dificuldade maior está em qualificar os atos que não geram confusão. Como se verá, tais casos são mais raros, e cobertos por maior disfarce e criatividade, não sendo fácil sua apuração.

Por fim, sem qualquer pretensão de esgotar o tema, para aplicar o resultado da revisão bibliográfica, serão indicados atos de imitação que possuem grande potencialidade de serem qualificadas como condutas concorrenciais desleais, ainda que não tenham como objetivo, nem resultado, a confusão no mercado.

\section{METODOLOGIA}

O presente trabalho, após introduzir o tema a ser exposto, e apresentar a metodologia de abordagem, passará a fazer uma revisão bibliográfica referente ao conceito de concorrência desleal, para que desde já se tenha em mente sua definição aproximada. A revisão trará à baila os conceitos tradicionais da mais festeja doutrina relativa ao direito da propriedade intelectual. Em seguida a revisão bibliográfica buscará por pressupostos que ajudem a caracterizar os atos de concorrência desleal e classificá-los como tais. Com base em toda revisão bibliográfica, serão indicados e comentados exemplos práticos de atos de imitação não confusivos que, com base nas definições e pressupostos estudados, podem ser configurados como atos de concorrência desleal. 


\section{CONCORRÊNCIA DESLEAL}

Tendo e vista o amplo caráter da concorrência desleal e as "sinnúmeras" (TINOCO SOARES, 2006) formas que ela pode se apresentar, resta uma tarefa difícil limitá-la em uma conceituação pré-definida.

Apesar da dificuldade, renomados autores apresentaram suas definições sobre concorrência desleal, como demonstra a compilação realizada por Alberto Luís Silva, valendo-se de três renomados doutrinadores:

PONTES DE MIRANDA a define como: Ato reprimível criminalmente e gerador de pretensão à abstenção ou à indenização, ou somente gerador de pretensão à abstenção ou à indenização, que se praticou no exercício de alguma atividade e ofende à de outrem, no plano da livre concorrência.

GAMA CERQUEIRA aduz como sendo aquela praticada por competidor que, agindo através de meios desonestos e contrários às boas normas, prejudica os negócios alheios ou desvia clientela para proveito próprio.

CELSO DELMANTO, citando Edward S. Rogers: a concorrência desleal se caracteriza por truques sujos (dirty tricks) impingidos pelo competidor desleal que os aplica para ganhar deslealmente a corrida (CAMALIER DA SILVA, 2009).

O professor Ascensão, por sua vez, ao decorrer sobre o tema indica que "a essência está nas situações em que alguém procura vencer no mercado, não pela sua própria contribuição, mas explorando as contribuições alheias" (ASCENSÃO, 1997).

Para o professor Carlos Henrique de C. Fróes, "a variedade dos delitos de concorrência desleal dificulta, sobremaneira, uma definição que possa abrangê-los" (FRÓES, 2001). Assim, não por acaso, as definições sobre o tema são bastante amplas. Como já defendia o professor, "o concorrente desleal, qualquer que seja a modalidade de ilícito, não planta a árvore, mas colhe os frutos da árvore alheia, à revelia de seu dono" (FRÓES, 2001).

Gama Cerqueira já nos alertava que a realidade supera qualquer conceituação sobre a concorrência desleal, pela possibilidade de sempre surgir novas formas de concorrência, que, antes, nem se suspeitava existir, superando qualquer previsão (CERQUERIRA, 1982). Com efeito, não há como se enumerar uma lista de atos de concorrência desleal. Certamente, qualquer lista "estaria fadada ao fracasso, uma vez que não há limites para imaginação humana" (MENDES, ALMEIDA JUNIOR, 2013).

Professor Denis Borges, ratifica o entendimento de que uma listagem de casos considerados como atos de concorrência desleal não será perfeita (BARBOSA, 2003). 
Das considerações acima, depreende-se que as possibilidades de condutas desleais na concorrência são as mais variadas possíveis. Para que sua apuração não fique a mercê de subjetivismos, importante notar os critérios e indícios abraçados pela doutrina e jurisprudência.

Para conduzir o estudo respeitando o corte proposto, desmembra-se a concorrência desleal entre suas duas características, a saber, concorrência e deslealdade. Como efeito, o professor Ascarelli já simplificava dessa forma: "La disciplina della concorrenza sleale colpisce, abbiam visto, gli atti di concorrenza e quando sleali" (ASCARELLI, 1970).

\subsection{Teorias para Apuração da Deslealdade}

A concorrência, em sí, não será objeto do presente estudo. A partir desse momento, qualquer referência à concorrência deve ser considerada como conconrrência efetiva ente entes privatos que exercem suas atividades no mesma àrea de atuação, no mesmo àmbito geográfico e ao mesmo tempo.

Já para a configuração do ato de deslealdade na concorrência é preciso que o ato tido como desleal seja "contrário aos usos honestos em matéria industrial ou comercial" no dizer da Convenção de Paris ${ }^{1}$.

Segundo Denis Borges, o que se vem ser entendido como ato leal ou desleal na concorrência resulta da conformidade ou não do comportamento do competidor ao padrão esperado, não se apurando, portanto, apenas o dolo do competidor, mas sim a existência de deslealdade (BARBOSA, 2003).

Com efeito, a revisão bibliográfica da segunda parte deste estudo dará foco a este ponto específico, em uma tentativa de indicar meios de se apurar a deslealdade no comércio e verificar, especificamente, quando em atos de imitação não confusivos haverá "a existência de deslealdade" ou "qualificadora específica".

Nesse ponto, renomados professores apontaram para "qualificadoras especificas" que indicariam a deslealdade da conduta, uma vez que, a imitação por si só, não teria o condão de configurar o ato de imitação como desleal. Já dizia o mestre Ascensão: "A imitação, como grande fundamento do progresso social, é livre (...)" (ASCENSÃO, 1996)

Portanto, é necessário ter cautela para averiguar quais são os critérios e parâmetros adotados para avaliar os atos de imitação, sob pena de se "reconstituir judicialmente monopólios que o legislador não quis" (LEITÃO, 2001).

1 Conforme seu artigo 10bis. 
Neste estudo, serão indicados critérios que podem ser úteis na arte de apurar a deslealdade do agente imitador. Contudo, não há qualquer pretensão de esgotá-los, tratam-se, a bem da verdade, de algumas teorias.

\subsubsection{Expectativa Razoável de Comportamento do Mercado.}

O Supremo Tribunal Federal, em interpretação das exposições do advogado italiano Natalino Irti sobre a definição de mercado, faz a seguinte constatação:

“(...)é uma ordem, no sentido de regularidade e previsibilidade de comportamentos, cujo funcionamento pressupõe a obediência, pelos agentes que nele atuam, de determinadas condutas. Essa uniformidade de condutas permite a cada um desses agentes desenvolver cálculos que irão informar as decisões a serem assumidas, de parte deles, no dinamismo do mercado" (BARBOSA, 2011).

A contrario sensu, os comportamentos não regulares e não previsíveis não estariam em conformidade com a ordem no mercado. Dessa forma, a imprevisibilidade de Irti pode ser usada para identificar os agentes que buscam tirar proveito de situações não previstas para determinado mercado.

Nessa linha de raciocínio, Denis Borges desenvolveu o entendimento de que não se pode frustrar a "expectativa razoável de receita futura", ocasionado pela conduta concorrencial padrão de determinado segmento de mercado. O comportamento inaceitável pelas práticas usuais é vedado pelo Direito, que protege os interesses razoáveis. Conclui o professor: deve-se suportar o usual, o esperado, mas não o inesperado e o excessivo (BARBOSA, 2003).

Com efeito, há um padrão de condutas em cada mercado. O novo competidor ao entrar em determinado segmento já conhece, ou deveria conhecer, suas práticas usuais e assim monta sua estratégia de atuação com base na expectativa de comportamento de seus concorrentes. Em seu artigo a Doutrina da Concorrência, o professor Denis Borges conclui que não seria a lei que define os limites da concorrência, mas, em realidade, as praticadas dos demais concorrentes de um mercado específico, localizadas no tempo e lugar (BARBOSA, 2002).

Sob o ponto de vista da imitação, percebemos que mercados já possuem características comuns, elementos que, embora não necessários para o produto ou oferta do serviço, são amplamente utilizados e esperados pelos concorrentes.

Desse modo, condutas não previstas, como imitações de elementos não usuais, não necessários e não funcionais em determinado mercado, podem ser consideradas como 
desleais, uma vez que não eram previstas e assim frustram as expectativas razoáveis do agente imitado que não esperava um comportamento de imitação fora dos padrões de mercado.

As consequências de tais atos podem chegar até à retirada do imitado que após investir para se destacar no mercado não consegue apresentar preço competitivo em comparação aos imitadores que desqualificaram a característica imitada, até então única, em determinado segmento.

Do exposto, pode se concluir que o princípio da imprevisibilidade é de grande ajuda para determinar se a imitação pode ser considerada como desleal, ou um simples exercício da liberdade de imitação.

\subsubsection{Princípio da Própria Prestação.}

Não há qualquer novidade em relação ao uso do princípio da prestação, desenvolvido pela doutrina alemã, para caracterização da deslealdade em condutas de imitação. José de Oliveira Ascensão no sugestivo artigo “O Princípio da Prestação: Um Novo Fundamento para a Concorrência Desleal?", apontava este como critério para apuração da fronteira entre a liberdade de imitação e a concorrência desleal (ASCENSÃO, 1996).

O princípio da prestação nada mais é do que a competição por meio dos próprios esforços. Dessa forma, busca o competidor vencer no mercado por sua própria contribuição.

Sobre o tema, após breve explanação, Carnelutti faz uma interessante analogia com uma corrida de cavalos, que, permite-se, transcrever aqui na íntegra:

los concurrentes corren juntos hacia una misma meta; vence quien llega primero. El juego es leal, en tanto cada uno se sirve, para adelantar a los demás, de sus propias fuerzas; cuando se hace así, el derecho asiste impasible a la competencia, como los jueces a una carrera. Pero el derecho no permite que alguno de los concurrentes impida a otro servirse de sus propias fuerzas ni menos que trate de utilizar las fuerzas de él; por ejemplo, cuando se trate de una carrera de caballos, que le encoja o le cambie la cabalgadura (CARNELUTTI, 1945).

Seguindo sua exposição, a doutora espanhola Eva Pérez conclui que quem não compete segundo seus próprios esforços, competirá de forma contrária ao princípio da prestação, e portanto, de modo desleal (PÉREZ, 2003).

Sob esse ponto de vista, os atos de imitação, embora, em tese, livres, devem ser observados, pois podem indicar a tentativa de se obter vantagem por meio do esforço alheio. Ainda que não se pretenda confundir a clientela, o imitador visa a evitar gastos e riscos para, de forma parasitária, ganhar espaço no mercado apenas pelo aproveitamento de prestações 
alheias, sem os investimentos da criação e os riscos da inovação (MENDES, ALMEIDA JUNIOR, 2013).

Sobre a possibilidade de aplicação do principio da prestação em casos de imitação que não geram confusão, o professor Ascensão ensina:

Estão aqui em causa as situações em que a imitação não implica todavia a indução em erro do consumidor. Se assim não fosse, o acto seria repelido por força da confusão, que representa um fundamento típico. Mas pode haver o mero aproveitamento de prestações alheias, sem se criar o risco de confusão. É o que se dá quando um concorrente copia a acentuação empresarial do outro, actuando porém ostensivamente em próprio nome (ASCENSÃO, 1996).

Por todo o exposto, podemos concluir que "o princípio da prestação nos dá um critério auxiliar de solução, à luz do qual avançaremos melhor na difícil distinção, entre os actos de aproveitamento, dos que representam livre imitação e dos que trazem concorrência desleal, por serem parasitários" (ASCENSÃO, 1996).

\section{ALGUNS ATOS DE IMITAÇÃO NÃO CONFUSIVOS}

Sem qualquer pretensão de esgotar as possibilidades pelo tema, a exposição que segue trata de casos nos quais a imitação tem como objetivo parasitar o líder de mercado, seja por i) copiar ostensivamente elementos não necessários e de fácil absorção pelo consumidor, ou ii) imitar sistematicamente o agente que atua com inovação.

Ao tecer comentários sobre a lei de concorrência desleal espanhola, Concepción Molina esclarece que o artigo 11 da referida lei, além de tratar dos atos de imitação que geram confusão, também proíbe i) a imitação que tem a pretensão, ainda que presumida, de se aproveitar de forma indevida da reputação ou esforços alheios e ii) a imitação sistemática quando ela tem como objetivo impedir ou criar obstáculos para a afirmação de um concorrente no mercado (MOLINA BLAZQUEZ, 1993).

Nessa linha, iremos focar em duas espécies de atos de imitação não confusivos: i) imitação de elementos não necessários, quando a estes é agregado valor (e quando esta imitação pressupõe um aproveitamento indevido de esforços alheios) e ii) imitação sistemática para impedir ou obstaculizar a afirmação no mercado de um concorrente (concorrência parasitária).

\subsection{Imitação de Elementos não Necessários - Valor Econômico}


A imitação de elementos não necessários para a comercialização de determinado bem ou oferecimento de determinado serviço, usualmente, pode criar confusão no mercado por induzir o consumidor a erro. No entanto, este artigo irá focar nas intenções do e consequências geradas pelo imitador que, apesar de copiar elementos não necessários de seu concorrente, normalmente o líder de mercado, emprega sua marca ou outro elemento que, teoricamente, impediria a confusão.

Contudo, como abordado ao longo desse artigo, ainda que a possibilidade de confusão seja remota, ou até inexistente ao consumidor médio em situações regulares, poderá haver deslealdade na conduta do imitador.

Nesse contexto, as cores, em diversos casos, são bons exemplos de elementos não necessários dotados de valor econômico pela ação publicitária de competidor. As cores marrom, azul claro, e rosa, devido ao considerável investimento de algumas empresas passaram a ter valor nos segmentos de entrega rápida, joias e alvejante, respectivamente.

Por certo, um concorrente que imite tais cores correrá sérios riscos de ter sua imitação vista como ato confusivo, uma vez que tais cores estão intimamente relacionadas a determinadas empresas e não possuem qualquer relação natural com os serviços e produtos indicados.

No entanto, é possível que o concorrente adote tais cores, porém, com um sinal distintivo próprio em evidência, capaz de efetivamente afastar a possibilidade de confusão pelo consumidor comum. Tal subterfúgio poderá descaracterizar o ato como confusivo, mas ainda se questiona com relação à sua deslealdade.

Com efeito, diante do investimento da UPS e a qualidade dos serviços por ela prestado, a cor marrom passou a ser sinônimo de entrega rápida ${ }^{2}$. Ainda que um concorrente se diferencie no mercado, mesmo sem conhecê-lo o consumidor saberá, apenas pela cor, que se trata de um outro serviço de entrega rápida, tal como UPS, porém de outro fornecedor. Esse rápido reconhecimento possui notável valor de mercado, e é um diferencial concorrencial.

Nessa hipótese o reconhecimento se deu inteiramente por meio de trabalho e esforço alheio, o que já pode ser considerado como uma evidência de deslealdade. $\mathrm{O}$ imediato reconhecimento do serviço prestado, sem a necessidade de qualquer investimento coloca o imitador com vantagem competitiva considerável.

2 Assim como o azul claro, pelo investimento da Tiffany \& Co, passou a simbolizar joias de alta qualidade e o rosa passou, pelo investimento da Reckitt Benckiser, a simbolizar alvejante eficiente na remoção de manchas difíceis. 
O imitado se beneficia do enriquecimento sem justa causa às custas do prestígio do líder do segmento de mercado, o que é expressamente vedado pelo ordenamento jurídico brasileiro ${ }^{3}$.

Não há dúvidas de que, ao se assemelhar ao líder de seu segmento, o imitador terá um reconhecimento do consumidor sem que tenha investido para tanto. Frise-se que abordamos a imitação de elementos não necessários, não dotados de efeitos técnicos e também que ainda não sejam de uso comum ou vulgarizado pelos concorrentes, mas que, pelo investimento do imitado o elemento passou a ter valor econômico, e por esse exato motivo, passou a ser cobiçado por seus concorrentes.

Quem assim age busca evitar investimentos para o reconhecimento de sua marca pelo consumidor. Não será preciso investir em publicidade e propaganda, bastaria, por exemplo, usar uma forte cor empregada característica e originalmente pelo líder do mercado que o consumidor saberá se tratar de um produto da mesma espécie.

Além disso, as semelhanças visuais podem causar impactos bastante negativos na mente do consumidor, prejudicando diretamente e de forma efetiva o imitado. Com efeito, um dos objetivos desse expediente - imitação de elementos não necessários com valor econômico - é desgastar as características peculiares não protegidas pelo direito de exclusividade para que, assim, o concorrente imitado veja diminuídos seus elementos característicos e únicos, e o imitador possa se assemelhar ao líder de mercado.

Embora os produtos e serviços sejam identificáveis, pelas caracteristicas visuais comuns, fatalmente será criada a impressão na mente do consumidor de que "tudo é igual", "qualquer um serve" (BARBOSA, 2011).

Ainda, o imitador, nesses casos, obterá uma vantagem indevida sobre os demais concorrentes que optaram por não fazer uso dos elementos característicos alheios.- embora esses elementos por si, não sejam elementos distintivos.

O judiciário brasileiro já teve oportunidade de se pronunciar sobre o assunto:

No caso concreto, o foco do reclamo da autora é a semelhança entre as embalagens dos produtos da ré e os seus, sob dois prismas: a) o primeiro, de supostamente induzir os consumidores em erro, traduzindo um injusto desvio de mercado; b) o segundo, de parasitismo e proveito do prestígio alheio.

O perito judicial, analisando as embalagens das latas de creme de leite comercializados pelas partes, concluiu pela relativa semelhança entre os pares de produtos comparados.

3 Código Civil, Lei 10.406/02 - Art. 884. Aquele que, sem justa causa, se enriquecer à custa de outrem, será obrigado a restituir o indevidamente auferido, feita a atualização dos valores monetários. 
O exame atento do laudo pericial revela que as embalagens de creme de leite utilizadas pela ré remetiam diretamente às embalagens da autora, que primeiro delas se utilizara e é líder de mercado.

Tenho dúvidas se o consumidor pode ser levado a erro pelas semelhancas das embalagens. Isso porque, apesar da similitude de cores e de figuras, os produtos têm as marcas "Nestlé"."Parmalat" e "Glória" ostensivas nos rótulos, que, de algum modo cumprem papel diferenciador.

Forçoso reconhecer, porém, que as evidentes semelhanças existentes não eram necessárias, nem cumpriam qualquer fim social relevante.

Pode-se até alegar que a fruta morango guarda certa associação com creme de leite. O que me desagrada não é o uso isolado da fruta, mas sim somado à similitude de cores azul e branco, o jorro do leite, enfim toda a composição da embalagem, que remete inegavelmente ao produto concorrente.

É notório que haveria uma associação entre os produtos, decorrente da similitude da disposição das cores e imagens entre ambos, e estou convencido que essa parecença foi deliberadamente desejada pela ré, ao alterar as embalagens, atendendo a estudo de mercado.

Fato incontroverso, mais, que as rés alteraram suas embalagens, após pesquisa de mercado. Não vejo razão plausível para a mudança, aproximando as novas embalagens daquela idealizada e construída pela líder de mercado.

A proteção à marca deve ser vista sob duplo aspecto. Um é evitar o erro, a confusão do consumidor; outro é evitar o parasitismo, o enriquecimento sem causa à custa do prestígio de marca alheia."

(TJSP, Ac 994.07.115467-5, 4o Câmara de Direito Privado do Tribunal de Justiça de São Paulo, Des. Francisco Loureiro, 25 de fevereiro de 2010) (grifamos).

Como pode ser observado na decisão supracitada, embora a parte autora tenha alegado que as embalagens poderiam ensejar confusão perante os consumidores, o Ilustre Desembargador demonstrou claramente que em seu entendimento, apesar dos elementos imitados, não haveria uma real possibilidade de confusão, uma vez que nas embalagens ostentava-se, claramente, os sinais distintivos dos concorrentes.

Por outro lado, o desembargador deixou claro que a imitação de elementos não necessários, ainda que não protegidos por direito de exclusividade, estabelece uma notória associação entre os produtos, concluindo que tal fato se deu de forma deliberada para se aproximar do líder de mercado e obter vantagens.

Pode-se concluir que a obtenção de vantagens pelo imitador se dá porque o imitado agregou valor econômico aos elementos não necessários. No caso da decisão acima, a 
combinação de azul e branco com jorro de leite no morango sempre esteve disponível para os atuantes no mercado de creme de leite, no entanto, só passou a ser cobiçada quando tal combinação passou uma associação com o líder de mercado, pois, assim, passou a representar as vantagens econômicas indicadas nesse artigo.

Ao analisarmos o caso concreto sob os aspectos dos princípios anteriormente mencionados, observamos que ambos são aplicáveis.

Afinal, não é esperado no mercado que seus agentes padronizem o rótulo criado pelo líder do segmento, tampouco seria padronizar suas cores predominantes, seu formato peculiar, dentre outros elementos, ainda que não passíveis de proteção isoladamente. Resta claro que imitações nesse sentido fogem da previsibilidade para o mercado, pois não fazem parte das condutas leais que se espera de concorrentes.

De igual modo, "se a imitação se concentra em elementos não-necessários para a eficiência da prestação própria, mas apenas úteis para parasitar o prestígio alheio, comete concorrência ilícita"(BARBOSA, 2011).

\subsection{Imitação Sistemática - Concorrência Parasitária}

Segundo Eva Pérez, o primeiro caso envolvendo a imitação sistemática foi resolvido pela Corte de Cassação da Itália, que qualificou essa conduta como concorrência parasitária (PÉREZ, 2003).

Nessa linha, para caracterização da deslealdade na imitação sistemática, não é necessário que ocorra confusão no mercado. Nessa modalidade, o objetivo do agente é se beneficiar de inovações que lograram obter êxito, sem, contudo, assumir os custos da criação ou riscos inerentes à conduta inovadora.

Marcus de Almeida bem exemplifica essa situação, razão pela qual pede-se vênia para transcrever aqui sua narrativa:

(...) uma determinada empresa do ramo de laticínios, resolve colocar no mercado um yogurt voltado para crianças. Por óbvio, tal produto deve ser adaptado para atingir o público desejado, no caso, as crianças. Desta feita, a equipe técnica desenvolve um produto mais denso que o yogurt comum, justamente para que a criança quando comer, não venha a se sujar.

Posteriormente, é necessário encontrar um sabor que agrade à clientela, uma vez que o sabor natural do produto por certo não atenderia às exigências do mercado almejado. Assim, após pesquisas com o público-alvo, chega-se ao sabor próprio, por exemplo: morango. 
Continuando o desenvolvimento, percebe-se que a embalagem padrão do produto original é muito grande para o novo público, de sorte que certamente acabaria sobrando, causando desperdício nada desejável para os pais das crianças.

Por conseguinte, após novos estudos encontra-se o tamanho correto para acondicionar o produto. Dando seguimento, conclui-se que é necessário apresentar um valor nutricional ao produto para que o mesmo se torne convidativo frente ao custo que deverá ser arcado pelos pais das crianças.

Após gasto muito tempo e dinheiro, o produto é finalmente colocado à venda, por meio de uma grande campanha publicitária. Passados alguns dias, o resultado é um sucesso de vendas, muito embora o preço não seja dos mais baixos, justamente em face da necessidade de cobrir todos os gastos advindos do desenvolvimento do produto.

O concorrente, observando a nova mercadoria colocada no mercado, vê a possibilidade de um ganho abraçando parte da clientela, sem contudo, causar confusão e lança seu produto com as mesmas características do original, ou seja, a mesma densidade, sabor, tamanho da embalagem e com grande vantagem, preço menor.

Ora, parece claro que o preço apresentado pelo concorrente parasitário parece ser menor, uma vez que não teve que investir dinheiro nem tempo para desenvolver o produto, aproveitando os esforços sem custo algum, além de não correr riscos (ALMEIDA, 2004).

Como se denota, o imitador busca tirar proveito das inovações do concorrente de modo a se aproveitar do esforço alheio, sem assumir o risco da inovação e os custos da criação.

A Lei de Concorrência Desleal Espanhola ${ }^{4}$ inovou ao indicar, expressamente, a imitação sistemática como conduta reprovável com base na concorrência desleal. Em seu texto, observamos importantes ressalvas:

Actos de imitación.

\section{$(\ldots)$}

3. Asimismo, tendrá la consideración de desleal la imitación sistemática de las prestaciones e iniciativas empresariales de un competidor cuando dicha estrategia se halle directamente encaminada a impedir u obstaculizar su afirmación en el mercado y exceda de lo que, según las circunstancias, pueda reputarse una respuesta natural del mercado.

\footnotetext{
4 ESPANHA, Ley No 3/1991, de 10 de enero de 1991, de Competencia Desleal (modificada por última vez por la Ley $\mathrm{N}^{\mathrm{o}}$ 29/2009, de 30 de diciembre de 2009). Disponível em: <http://www.wipo.int/wipolex/en/text.jsp?file_id=267675> Acesso em 19/01/2014.
} 
Molina, ao comentar a lei espanhola sobre o tema, esclarece que a imitação servil tratada na legislação se refere à concorrência parasitária que, por sua vez, seria caracterizada pela imitação das atividades e das iniciativas empreendidas por um concorrente. No entanto, faz a ressalva de que imitação deve exceder uma resposta normal do mercado e, além disto, procurar impedir a afirmação no mercado dos concorrentes (MOLINA BLAZQUEZ, 1993).

Conclui-se, assim, que a Lei espanhola apontou certas delimitações para que a imitação sistemática seja considerada desleal, não sendo a imitação sistemática em si uma qualificadora específica para caracterizar a deslealdade da imitação. Primeiramente, ela deve ter o objetivo de impedir ou obstar a afirmação do competidor, e em segundo lugar, deve exceder o que pode ser compreendido como uma resposta natural do mercado, o que nos leva a concluir, ainda, que a previsibilidade de conduta no mercado também exerce uma importante função para que possamos qualificar a imitação sistemática como ato desleal, e, portanto, reprovável.

Tendo como base o supracitado princípio da prestação, o professor português Ascensão assim aborda o tema:

Quando surge porém o carácter qualitativo da imitação, que leve a considerar que se trata de um acto de concorrência desleal?

Uma hipótese significativa é-nos dada pela concorrência parasitária. O conceito foi desenvolvido pela doutrina italiana. Não bastaria a imitação de elementos isolados, seria necessário que a concorrência seguisse servilmente, contínua e globalmente a actividade empresarial alheia.

Diríamos assim que a concorrência parasitária só surge quando a empresa não dá a sua própria contribuição, porque se limita a copiar a prática empresarial alheia.

O exemplo ajuda-nos a reencontrar o princípio da prestação. Este permite-nos entender que não são actos isolados de imitação (a pintura das fachadas com o mesmo estilo, as vestimentas das empregadas) que excluem que cada empresa apresente as suas próprias prestações. A concorrência só é caracterizada quando uma empresa, em vez de actuar segundo uma linha própria, se limita, parasitariamente, a seguir os traços da linha alheia. É então que não se impõe no mercado pela própria prestação, mas por prestações alheias (ASCENSÃO, 1996).

Além das ressalvas acima, segundo Pérez, para que haja imitação sistemática de forma ilícita e não desejada no mercado, faz-se ainda necessário que o competidor imitado atue com constante inovação e que suas práticas comerciais sejam perseguidas em curto espaço de tempo e sucessivamente pelo mesmo concorrente (PÉREZ, 2003). 
Portanto, como base na jurisprudência italiana, legislação e doutrina espanhola, bem como doutrina portuguesa, a imitação sistemática pode constituir um ato de concorrência desleal não confusivo, porém, a mera imitação sistemática não deveria ser considerada como uma qualificadora específica. Os autores aqui trazidos indicaram outros elementos que são capazes de qualificar a imitação sistemática como desleal.

Com relação às consequências da imitação sistemática, as advogadas Cristiane Manzueto e Fernanda Tavares Dias apontam que, nesta hipótese, o parasita não tem como objetivo eliminar o agente do qual se aproveita, pelo contrário, há um interesse em que o imitado se permaneça forte para que o imitador possa se alimentar se alimentar de suas ideias, criações e investimentos. No entanto, concluem as advogadas que o prejuízo do concorrente imitado é uma consequência inevitável (MANZUETO, TAVARES DIAS, 2013).

Com efeito, a imitação sistemática inibe a constante inovação no segmento mercadológico, prejudicando, além do imitado, o próprio consumidor:

En el supuesto de la imitación sistemática, el acto de imitación afecta, en primera instancia, al proprio competidor imitado (pionero), pero también el consumidor se ve negativamente afectado, en la medida que los efectos perjudiciales que a largo plazo provoca la imitación sistemática repercutirán negativamente en el mismo (PÉREZ, 2003).

Ainda segundo Eva Pérez, a imitação sistemática pode chegar à eliminação do competidor pioneiro, uma vez que a constante inovação aumenta os preços de seu produto, o que não reflete na concorrência que se limita a copiar sistematicamente suas inovações.

Portanto, imperioso que o imitado tome as medidas que julgar cabíveis de modo rápido, para que a postura do imitador sistemático não seja considerada pelos demais competidores como uma resposta padrão do mercado, mudando os parâmetros de expectativa razoável de receita futuras dos novos entrantes ao mercado.

\section{CONCLUSÃO}

Logo nas primeiras definições sobre o ato de concorrência desleal, mostrou-se difícil delimitá-lo, sendo seu alcance por demais abrangente e com variações significativas em cada mercado. Observou-se que qualquer limitação predefinida estaria fada ao fracasso, afinal, a conduta desleal encontra limite apenas na imaginação humana.

Muito embora dentre tantas hipóteses de conduta desleal, o presente artigo tenha sido focado apenas nos atos de imitação, percebeu-se que as possibilidades de condutas e seus objetivos são os mais diversos. 
Cada caso específico de imitação deve ser apurado com bastante cautela para que possa ser verificado se o imitador age nos limites de sua liberdade de concorrer e imitar, ou, se, ao contrário, há elementos (qualidades específicas) que evidenciem uma conduta desleal perante seus concorrentes.

O conceito de expectativa razoável de receita futura com base no comportamento esperado do mercado, como o princípio da prestação dos próprios esforços podem ser ferramentas úteis para verificar, caso a caso, quando age o imitador com deslealdade.

Com base nessas teorias, foi possível concluir que a imitação de elementos não necessários para a comercialização de certo produto ou oferta de determinado serviço, quando tais elementos são dotados de valores econômicos graças ao investimento do inovador - o que, por sinal, se torna o responsável por incitar a cobiça nos concorrentes - pode ser caracterizada como ato de concorrência desleal.

Ainda com base na presente revisão, foi possível trazer para interpretação da legislação brasileira os atos de imitação sistemática, também conhecidos como concorrência parasitária, uma vez que as teorias apontadas igualmente conduzem à caracterização da deslealdade deste ato, quando presente os elementos destacados, fazendo-se necessária a repressão a tais atos, conforme determinação legal.

De toda forma, para efetiva repressão aos atos de concorrência desleal com base nos atos de imitação não confusivos, depender-se-á da atuação e criatividade do agente jurídico, que deverá lidar com os limites aqui expostos para fazer valer o direito da parte inocente.

\section{REFERÊNCIAS}

ALMEIDA, Marcus Elidius Michelli de. Abuso do direito e concorrência desleal. São Paulo: Quartier Latin, 2004.

ASCARELLI, Tullio. Teoria de la concurrencia y de los bienes inmateriales. Itália: Casa Editorial, 1970.

ASCENSÃO, José de Oliveira. Concorrência desleal. Coimbra: Almedina, 2002.

ASCENSÃO, José de Oliveira. O princípio da prestação: um novo fundamento para a concorrência desleal? Separata da Revista da Ordem dos Advogados, Ano 56, I - Lisboa, Janeiro 1996.

ASSAFIM, João Marcelo de Lima. Aspectos do direito de defesa da livre concorrência brasileiro: a lei $\mathrm{n}^{\circ}$. 10.149/2000 e perspectivas de nova política. Revista da ABPI, Rio de Janeiro, $\mathrm{n}^{\circ}$ 68, p. 55-68, jan.fev. 2004. 
BARBOSA, Denis Borges. A doutrina da concorrência. 2002. Disponível em http: .denisbarbosa.addr.com arquivos concorrencia .doc> Acesso em 12/03/2012.

BARBOSA, Denis Borges. Concorrência desleal, e sua vertente parasitária. ago. 2011. Disponível em $\langle$ http://www.denisbarbosa.addr.com/arquivos/novidades/concorrencia_desleal.pdf $>$ Acesso em 12/03/2012. p.10.

BARBOSA, Denis Borges. Uma introdução à Propriedade Intelectual. 2a . Ed. rev. e atual. Rio de Janeiro: Lumen Juris, 2003.

BRASIL. Constituição da República Federativa do Brasil de 1988. Disponível em: <http://www.planalto.gov.br/ccivil_03/constituicao/constituicao.htm>. Acesso em: 18.10.2013

BRASIL. Lei no 10.406, de 10 de janeiro de 2002. Institui o Código Civil. Disponível em: <http://www.planalto.gov.br/ccivil_03/leis/2002/L10406.htm>. Acesso em: 18.10.2013

BRASIL. Lei $n^{o} 8.078$, de 11 de setembro de 1990. Dispõe sobre a proteção do consumidor e dá outras providências. Disponível em: <http://www.planalto.gov.br/ccivil_03/leis/18078.htm>. Acesso em: 20.12.2013

BRASIL. Lei $n^{\circ}$ 9.279, de 14 de maio de 1996. Regula direitos e obrigações relativos à propriedade industrial. Disponível em: <http://www.planalto.gov.br/ccivil_03/leis/L9279.htm>. Acesso em: 25.11.2013

BURST, Jean Jacques. Concurrence déloyale et parasitisme. França: Dalloz, 1993.

CABANELLA, Guillermo. El derecho argentino de la competencia desleal. Crítica y propuesta de reforma, "Derechos Intelectuales", nº 10.

CAMELIER DA SILVA, Alberto Luís. Aspectos cíveis da concorrência desleal no sistema jurídico brasileiro. [S.1.: s.n.]. In: LIMA, Luís Felipe Balieiro (Coord). Propriedade intelectual no direito empresarial. São Paulo: Quartier Latin, 2009, p. 231-269.

CAMELIER DA SILVA, Alberto Luís. Concorrência Desleal: atos de confusão. São Paulo: Saraiva, 2013.

CARNELUTTI, Francesco. Usucapión de la propiedad industrial. México: Porrúa, 1945.

CERQUEIRA, João da Gama. Tratado da Propriedade Industrial, vol. II, Rio de Janeiro: Revista Forense, 1982.

COMPARATO, Fábio Konder. Concorrência desleal. Revista dos Tribunais, n. 374, p. 29-35, jan. 1967.

CONVENÇÃO DA UNIÃO DE PARIS PARA PROTEÇÃO DA PROPRIEDADE INTELECTUAL. Disponível em <http://www.planalto.gov.br/ccivil_03/decreto/19901994/anexo/and1263-94.pdf>. Acesso em 02/02/2014

DELMANTO, Celso. Crimes de concorrência desleal. São Paulo: Bushatsky/EDUSP, 1975. 
ESPANHA, Ley $N^{o} 3 / 1991$, de 10 de enero de 1991, de Competencia Desleal (modificada por última vez por la Ley $\mathrm{N}^{\circ}$ 29/2009, de 30 de diciembre de 2009). Disponível em: $<$ http://www.wipo.int/wipolex/en/text.jsp?file_id=267675> Acesso em 19/01/2014.

FRÓES, Carlos Henrique de Carvalho. Evolução jurisprudencial da repressão da concorrência desleal. Anais do XXI Seminário Nacional da Propriedade Intelectual. Rio de Janeiro: ABPI, 2001 .

LEITÃO, Adelaide Menezes. Imitação servil, concorrência parasitária e concorrência desleal. Portugal: Almedina, 2001.

MANZUETO, Cristiane dos Santos, TAVARES DIAS, Fernanda Mósca. Concorrência desleal, concorrência parasitária e aproveitamento parasitário. In: A propriedade intelectual no novo milênio. São Paulo: ASPI, 2013.

MENDES, Paulo Parente Marques e ALMEIDA JUNIOR, José Roberto de. Concorrência desleal: atos de imitação sem indução em erro. In: ASSOCIAÇÃO INTERAMERICANA DA PROPRIEDADE INTELECTUAL. Derechos intelectuales. Colômbia: Legis, 2013. p.110128. Derechos intelectuales, 17.

MOLINA BLAZQUEZ, Concepción. Protección jurídica de la lealtad en la competencia. Madrid: Montecorvo SA, 1993

PÉREZ, Eva Domínguez. Competencia desleal a través de actos de imitación sistemática. Espanha, Navarra: Thomson Aranzadi. 2003.

SALOMÃO FILHO, Calixto. Direito concorrencial: as estruturas. São Paulo: Malheiros Editores, 1998.

TINOCO SOARES, José Carlos. Título. Tratado de propiedad industrial de las Américas. Buenos Aires, Lexis Nexis. 2006. 